\title{
The Journal and Academia
}

\author{
Eelco F. M. Wijdicks
}

Published online: 20 December 2011

(C) Springer Science+Business Media, LLC 2011

It is not so long ago- not longer than a century ago- that physicians started to apply a scientific method to the study of patients. Therefore, most of what we know-and make decisions on-is based on clinical observations by grandees in neurology and neurosurgery and not so much on rigorous clinical trials. This traditional form of knowledge acquisition remains important, but we need evidence that something works or-even better-helps the patient.

It is not so long ago - not longer than half a century ago- that patients with a severe brain injury were cared for on the ward until their demise. With significant improvement in neurological knowledge, we now provide comprehensive and complex care in a Neurosciences Intensive Care Unit and with considerable success. Although most of the early discoveries were made by nonneurointensivists, the reputation of several study groups is rising and all kinds of articles focused on the care of the neurocritically ill patient have appeared. It is good for any journal when we will know less and less about more and more (and not more and more about less and less).

The Neurocritical Care Society recognizes the academic side of the specialty very well, and this new year we open with a series of essays on the academics of Neurocritical Care and the Neurocritical Care Research Network. This administrative body is a serious attempt to streamline research and, in particular, large-scale clinical trials. In this issue we publish a series of thought-provoking articles about the aims and challenges of such an organization. Prior networks in general critical care have been very successful and there is no reason to doubt this initiative will be successful too.

E. F. M. Wijdicks ( $\square)$

Mayo Clinic, Rochester, MN, USA

e-mail: wijde@mayo.edu
It is not so long ago — not longer that a decade ago— that we started Neurocritical Care. But where does the Journal fit in, how will we advance the field and how can we maintain our academic credibility? Of course, the Journal should have an unbreakable link with Academia. In one respect, I thought it was simple and I would only look at scientific value. But $I$ hear the following questions: Is the Journal a commodity? Can we make more money with the Journal? Can this industry sponsor this publication? How can we "game" the impact factor?

My answer would be that these issues should not be uppermost on an Editor's mind. Neurocritical Care is here for exchange of ideas and important observations, for nuance and consideration of alternative views. We have no interest in promoting devices, instruments or other technology for the sole purpose of increasing revenue. Our purpose is curiosity and interest in the well-being of patients. We should be sincere academicians and our publications should advance our understanding of the field. That is the epitome to which we aspire. Any other way will cause distrust of our objectivity. These principles are sacrosanct. Scientific publications are our form of currency.

The impact factor of Neurocritical Care is slowly rising, and it will take time to become a "high impact" journal. There is a large body of literature on the strengths and weakness of the impact factor, but it is generally known that the impact factor favors papers with short citation lives, and the impact factor does not generally reflect utility of the article. Everybody knows the impact factor can be easily manipulated. Nevertheless, the impact factor will not disappear soon nor will advertisement of impact factors by journals stop. My main objective remains to just publish very good papers. A high impact factor will follow, but that should be a secondary goal. 
I recognize that the "built it so they'll come" argument may also have its problems and may lead to overconfidence. It remains a difficult balancing act. A good recent development is that Neurocritical Care is now available and translated in abstracted form in China. The number of institutions with access to Neurocritical Care increased dramatically from 3,550 in 2009 to 6,159 in 2010 .

In this area of new modernity, our publisher, Springer Science + Business Media, is keeping tabs on developments. The format of the journal may change in the digital age and who knows how you will read and digest all this information.
The journal has an attractive website with information on the most cited papers. This year will bring us an App. This year also will bring us video presentations by authors.

Again, with another year to come, I greatly thank the reviewers of manuscripts. These reviewers took the time to look at the submitted manuscripts despite being too busy in the unit, in the process of grant writing, traveling, soon going on vacation or having other overwhelming responsibilities. Despite all that, they agreed they would carefully assess the potential merit of a submitted manuscript, and they are listed below.

\section{Ad Hoc Reviewers 2011}

\author{
Nicholas Abend \\ Opeolu Adeoye \\ Imoigele Aisiku \\ Venkatesh Aiyagari \\ Paul Akins \\ George Alexiou \\ Fabio Andrade \\ Safdar Ansari \\ Fahad Aziz \\ Bulent Bakar \\ Andrew Baker \\ Helen Barkan \\ Mustafa Baskaya \\ Ronny Beer \\ Michael Bell \\ Randy Bell \\ Francis Bernard \\ Richard Bernstein \\ Eric Bershad \\ Federico Bilotta \\ Michel Bojanowski \\ Eric Bourekas \\ Ansgar Brambrink \\ Raf Brouns \\ Ross Bullock \\ Peter Campbell \\ Norbert Campeau \\ Raphael Carandang \\ Gianluca Castellani \\ Alfonso Cerase \\ Feng-Chi Chang \\ Jeff Chen \\ Arturo Chieregato \\ Charmaine Childs \\ Sherry Chou \\ Harry Cloft \\ Kevin Cockroft
}

Thiago Coelho
Frederick Colbourne
Jonathan Coles
Alfredo Conti
Jesse Corry
Claire Creutzfeldt
Marek Czosnyka
Jean de Oliveira
Bart Demaerschalk
Rajat Dhar
Christopher Eddleman
Jonathan Edlow
Jeremy Fields
Jeffrey Fletcher
Alexander Flint
Isabel Fragata
William Freeman
Jennifer Fugate
Sunil Furtado
Jaime Gasco-Tamari
Daniel Godoy
David Greer
Hillary Grocott
Bradley Gross
Ai Guo
Santiago Gutierrez
Mario Habek
John Halperin
Bridget Harris
Tomoki Hashimoto
Angela Hays
Matthieu Henry-Lagarrigue
Michael Hill
Holly Hinson
Damian Holliman
J. Stephen Huff
Andreas Hug

Ferdinand Hui

Olivia Hurtado

H. B. Huttner

Catalina Ionita

Jeffrey Jacob

Matthias Jaeger

Michael James

Tariq Janjua

S. Andrew Josephson

Tadashi Kaneko

Gregory Kapinos

Vasilios Katsaridis

Masahiko Kawaguchi

Salah Keyrouz

Joon-Tae Kim

Nebojsa Nick Knezevic

Sebastian Koch

Matthew Koenig

W. Andrew Kofke

Rainer Kollmar

Bradley Kolls

John Kuluz

Avinash Kumar

Gyanendra Kumar

Peter Lackner

Julius Gene Latorre

Andrea Lavinio

Kennith Layton

Christos Lazaridis

Vivien Lee

Stephane Legriel

Abhijit Lele

Joshua Levine

Zhaojian Li

Geoffrey Ling

Miklós Lipcsey

Juan Llompart-Pou 
Yahia Lodi

Yince Loh

Dana Lustbader

R. Loch Macdonald

Silvia Marino

Shearwood McClelland III

Nancy McLaughlin

Ankit Mehta

Paul Michel Mertes

Chad Miller

Michael Moussoutta

Susanne Muehlschlegel

Tatsushi Mutoh

Masao Nagayama

Andrew Naidech

Kazuma Nakagawa

Ron Neyens

Ivan $\mathrm{Ng}$

Thanh Nguyen

Marc Nuwer

Paul Nyquist

Mauro Oddo

DaiWai Olson

Berk Orakcioglu

Juan Padilla

Thanh Phan

Ornella Piazza

Konstantin Popugae

J. Javier Provencio

Corina Puppo
Louis Puybasset

Gail Pyne-Geithman

Girija Rath

Fred Rincon

Carlos Romero

Jeffrey Rosenfeld

Andrea Rossetti

Anand Rughani

Monica Saini

Edgar Samaniego

Daniel San-Juan

Asita Sarrafzadeh

Aarti Sarwal

Martin Savard

Clemens Schirmer

Stefan Schwarz

Keith L. Scott

Kiarash Shahlaie

Kevin Sheth

Lori Shutter

John Sims

Vineeta Singh

Martin Smith

Romain Sonneville

Erik St. Louis

Deborah Stein

Thorsten Steiner

Luzius Steiner

John Stover

Robert Stuart
Jose Suarez

Fabio Silvio Taccone

Muhammad Taqi

Isaac Tawil

John Tayek

Samuel Tisherman

Daoming Tong

Diederik van de Beek

Walter van den Bergh

Joukje van der Naalt

Panayiotis Varelas

Roland Veltkamp

Chethan Venkatasubba Rao

Deepti Vibha

Stacy Voils

Ingrid Wagner

David Wang

Jian Wang

Adam Webb

Nicolas Weiss

Linda Wendell

James White

Viroj Wiwanitkit

Wendy Wright

Joseph Ybarra

Midori Yenari

Gabriel Zada

Wendy Ziai

Alexander Zubkov 